\title{
Bronchogenic Cyst with High Carbohydrate Antigen 19-9 in the Cyst Fluid and the Serum
}

\author{
Yoshio Tokuchi, Hideaki Ukita, Yasuhiro Tsuneta, Youichi Nishiura, Wataru TaKahashi, \\ Terukuni KawaI, Hiroshi Isobe* and Yoshikazu KawaKami*
}

\begin{abstract}
A mass of $8 \mathrm{~cm}$ in diameter was revealed in the right upper lung field of a 46-year-old female patient. The chest $X$-ray film taken one year previously revealed only a linear shadow in the same position, which was thought to be a vacant cyst. The levels of carbohydrate antigen (CA) 19-9 in cyst fluid and serum were elevated, at 410,000 and $130 \mathrm{U} / \mathrm{ml}$, respectively. After surgical resection, serum CA19-9 returned to normal. Pathologically, the cyst wall was lined with bronchial epithelium with no evidence of malignancy. Immunohistochemical study revealed CA19-9 positivity in the bronchial epithelium of the cyst wall.

(Internal Medicine 37: 86-90, 1998)
\end{abstract}

Key words: congenital cyst, tumor marker

\section{Introduction}

Bronchogenic cysts are congenital anomalies that arise early in gestation from the budding of the developing respiratory systems (1). Bronchogenic cysts are seldom seen in adults, and most are thought to be asymptomatic and free of complications unless they become infected (2-4).

Carbohydrate antigen (CA) 19-9, a colorectal antigen detected by monoclonal antibody (5), is frequently elevated in patients with gastrointestinal carcinomas, pancreatic carcinomas or lung adenocarcinomas, and thus it is used as a tumor marker $(6,7)$. However, the relation between of CA19-9 and bronchogenic cyst has been previously reported in only a few cases (8-13).

Here, we report a patient with a bronchogenic cyst which caused an exceptionally elevated level of CA19-9 in the serum and cystic fluid, and which grew rapidly during a one-year period, appearing as an $8 \mathrm{~cm}$ mass shadow on chest X-ray film. These findings are important in recognizing the natural history of bronchogenic cysts.

\section{Case Report}

A 46-year-old woman was admitted to Konan hospital on June 14, 1994 due to an abnormal shadow on her chest X-ray film. Annual physical examinations for six years previously had shown no abnormalities on the chest X-ray films. She was a non-smoker and had no episode of exposure to excess dust or fumes. Her past history and family history were unremarkable.

On admission, physical examination profiled a mediumsized woman with body temperature of $36.7^{\circ} \mathrm{C}$. Her breath sound was weak in the upper right chest, but no surface lymph nodes were palpable. Laboratory examinations on admission gave the following results: Leukocyte counts $6,200 / \mathrm{mm}^{3}$, an erythrocyte sedimentation rate (ESR) of $11 \mathrm{~mm} / \mathrm{hr}$, and level of C-reactive peptide (CRP) within normal range. Biochemical and other serological examinations were all in the normal ranges. The serum level of CA19-9 was high at $130 \mathrm{U} / \mathrm{ml}$ (normal <37), but the serum level of carcinoembryonic antigen (CEA), human chorionic gonadotropin (HCG), neuron specific enolase (NSE) and squamous cell carcinoma-related antigen (SCC) were in the normal ranges (Table 1). The chest X-ray film on admission showed a mass as large as $8 \mathrm{~cm}$ in diameter in the right upper lung field (Fig. 1). Chest computed tomograph revealed a huge cystic mass immediately adjacent to the superior vena cava and the trachea. The density of the fluid inside the cyst was lower than in the adjacent muscle (Fig. 2).

We obtained approximately $300 \mathrm{ml}$ fluid from the cyst by percutaneous aspiration. The fluid was prulent and the level of CA19-9 was elevated at $410,000 \mathrm{U} / \mathrm{ml}$. The fluid protein was $5.5 \mathrm{~g} / \mathrm{dl}$; glucose, $0 \mathrm{mg} / \mathrm{dl}$; lactate dehydrogenase (LDH), 10,010 IU/l; leukocyte counts, $51,800 / \mathrm{mm}^{3}$ (Table 1). Examinations

From the Department of Internal Medicine, Konan Hospital, which is managed by Federation of Public Services and Affiliated Personnel Aid Associations and *the First Department of Medicine, Hokkaido University School of Medicine, Sapporo

Received for publication August 21, 1996; Accepted for publication September 25, 1997

Reprint requests should be addressed to Dr. Yoshio Tokuchi, the First Department of Medicine, Hokkaido University School of Medicine, Kita 15-jo, Nishi 7-chome, Kita-ku, Sapporo 060 
Table 1. Laboratory Findings

\begin{tabular}{lrlr}
\hline $\begin{array}{c}\text { Peripheral blood } \\
\text { White cells }\end{array}$ & $6,200 / \mathrm{mm}^{3}$ & Cyst fluid & White cells \\
Protein & $6.2 \mathrm{~g} / \mathrm{dl}$ & Protein & $51,800 / \mathrm{mm}^{3}$ \\
Glucose & $96 \mathrm{mg} / \mathrm{dl}$ & Glucose & $0.5 \mathrm{~g} / \mathrm{dl}$ \\
LDH & $229 \mathrm{IU} / l$ & LDH & $10,010 \mathrm{IU} / l$ \\
CA19-9 & $130 \mathrm{U} / \mathrm{ml}$ & CA19-9 & $410,000 \mathrm{U} / \mathrm{ml}$ \\
CEA & $0.9 \mathrm{ng} / \mathrm{ml}$ & CEA & $5.2 \mathrm{ng} / \mathrm{ml}$ \\
HCG & $<1.0 \mathrm{MIU} / \mathrm{ml}$ & HCG & $<1.0 \mathrm{MIU} / \mathrm{ml}$ \\
NSE & $3.6 \mathrm{ng} / \mathrm{ml}$ & NSE & $33 \mathrm{ng} / \mathrm{ml}$ \\
SCC & $<1.0 \mathrm{ng} / \mathrm{ml}$ & SCC & $120 \mathrm{ng} / \mathrm{ml}$ \\
\hline
\end{tabular}

LDH: lactate dehydrogenase, CA19-9: carbohydrate antigen 19-9, CEA: carcinoembryonic antigen, HCG: human chorionic gonadotropin, NSE: neuron specific enolase, SCC: squamous cell carcinomarelated antigen.

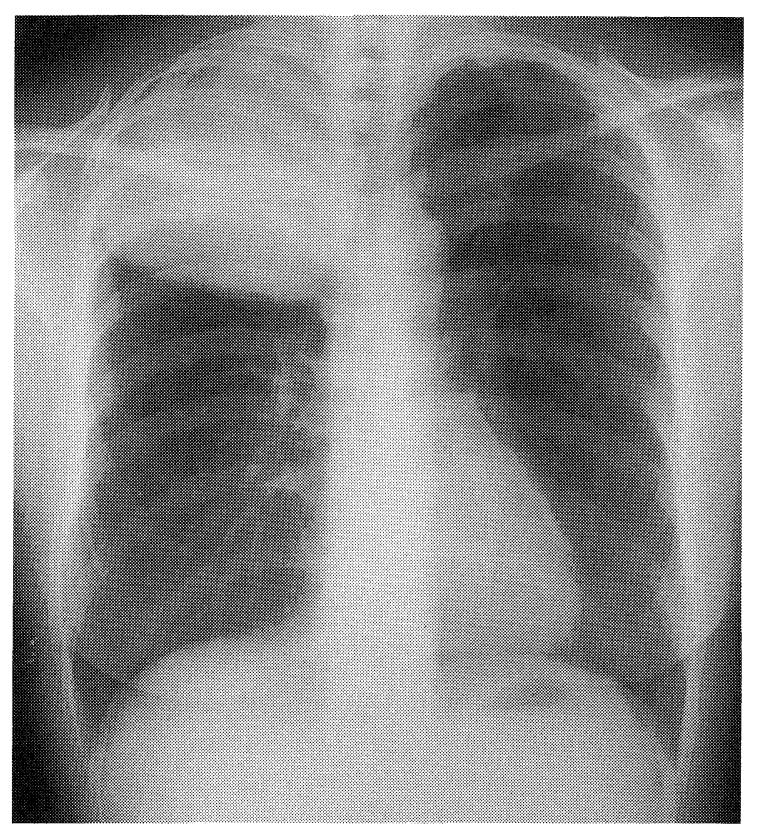

Figure 1. Chest X-ray film on admission. A huge mass was seen in the right upper lung field.

for malignant cells and bacteria, including mycobacterium tuberculosis, were negative.

After aspiration, the outer line of the cyst on the chest X-ray moved toward the mediastinum in the form of an arch (Fig. 3A, B). Upon close examination of the previous chest X-ray film taken one year earlier, a linear shadow was found in the inner zone which was suspected to be the outer line of the cyst, because there were no markings of pulmonary vessels inside the liner shadow (Fig. 3C). These facts indicated that the cyst was present at least one year previously, and further that communication between the airways and cyst was blocked, due to the large increase of the fluid volume inside. We suspected that this disease was bronchogenic cyst, however, malignant disease

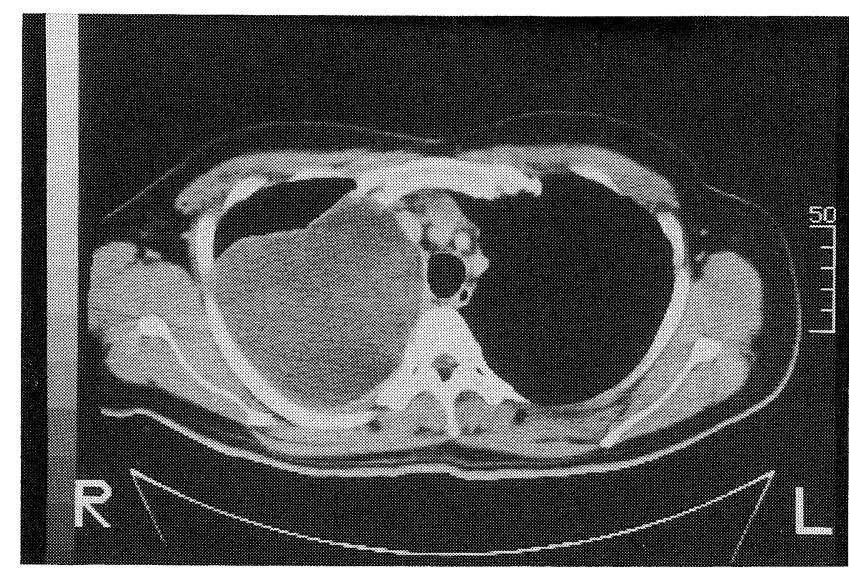

Figure 2. Chest computed tomograph on admission. A large mass was immediately adjacent to the superior vena cava and trachea.

could not completely be ruled out due to the elevated level of CA19-9.

On July 21, a thoractomy was carried out for the purpose of definite diagnosis and treatment. A cystic tumor of about $8 \mathrm{~cm}$ in diameter was enveloped by pleura pulmonalis, and pleura mediastinalis was found intact, enabling us to perform a complete resection.

Histologically, the cyst wall was composed of loose connective tissue lined with ciliated bronchial epithelium. Bronchial glands were also observed. No malignant lesions were found. In the area of adhesion with the lung, the cystic wall became thick with granulation tissue and included a few dilated bronchioles, but inflammatory cell infiltration in the area was slight (Figs. 4, 5). Immunohistochemical study with anti-CA19-9 monoclonal antibodies showed that ciliate epithelial cells, cells of the glands and the material in the lumina were strongly positive (Fig. 6). The post-operative serum level of CA19-9 returned to the normal range $(18.8 \mathrm{U} / \mathrm{ml})$.

\section{Discussion}

Bronchogenic cysts are benign tumors caused by abnormal budding of the bronchial tree (1). They are divided into two types according to location: mediastinal type and intrapulmonary type. The difference is due to the different times when the anomaly occurs in physical development (14-16). The present case was included in the intrapulmonary type because pleura mediastinalis was intact.

Monoclonal antibodies against CA19-9 can detect a monosialoganglioside antigen that is mainly present in gastrointestinal or pancreatic adenocarcinoma cells, and the serum level of CA19-9 is a more sensitive tumor marker than that of CEA of pancreatic cancers $(5,7)$. A small amount of CA19-9 is also present in normal cells, such as those of pancreatic duct, biliary duct, salivary gland ducts, and prostate and bronchial glands (17). Serum CA19-9 is sometimes known 

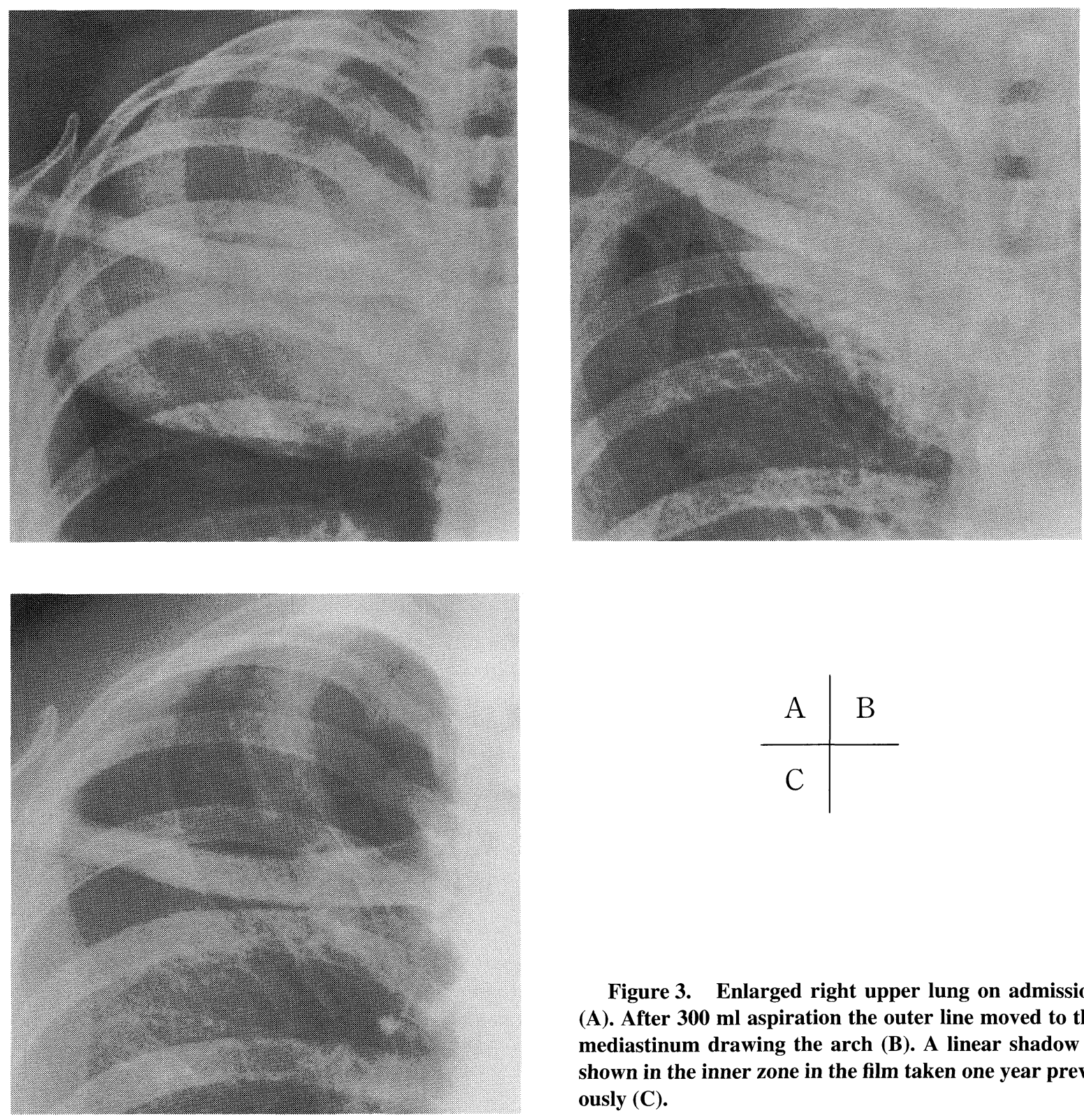

Figure 3. Enlarged right upper lung on admission (A). After $300 \mathrm{ml}$ aspiration the outer line moved to the mediastinum drawing the $\operatorname{arch}(B)$. A linear shadow is shown in the inner zone in the film taken one year previously $(\mathbf{C})$.

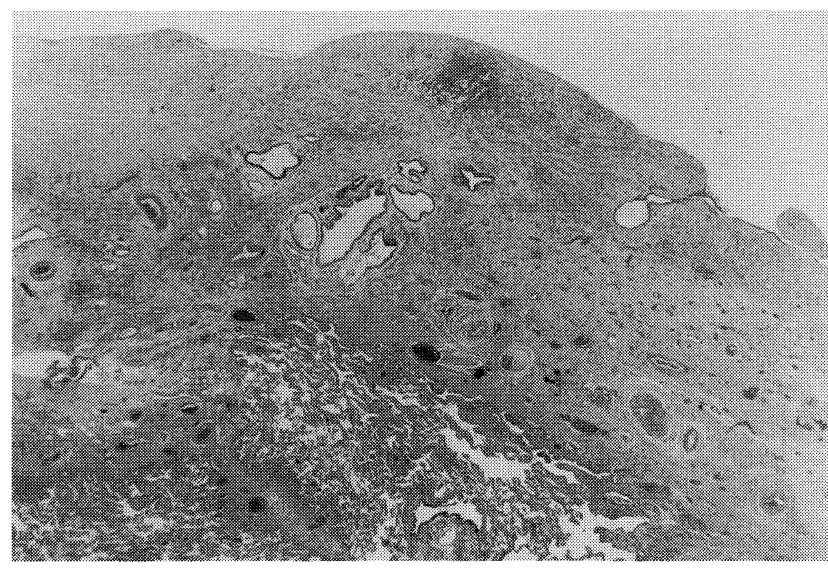

to be elevated to more than $100 \mathrm{U} / \mathrm{ml}$ in benign digestive tract diseases such as chronic pancreatitis or cholelithiasis (18). Okubo et al first reported a case of bronchogenic cyst with high level of CA19-9 in both serum and cystic fluid in 1989(8). Since then there have been five reports that indicate the relationship between bronchogenic cysts and increase of the CA19-9 level in the serum or the cyst fluid (9-13). The elevation in the levels of tumor markers in the cystic fluids is thought to be due to their production and accumulation in the cyst. Leakage of the cystic

Figure 4. Microscopic appearance of the cyst wall. There is a large amount of fibrous tissue and a few dilated bronchioles, but few inflammatory cells were seen between the cyst wall and the lung (HE stain, $\times 40)$. 


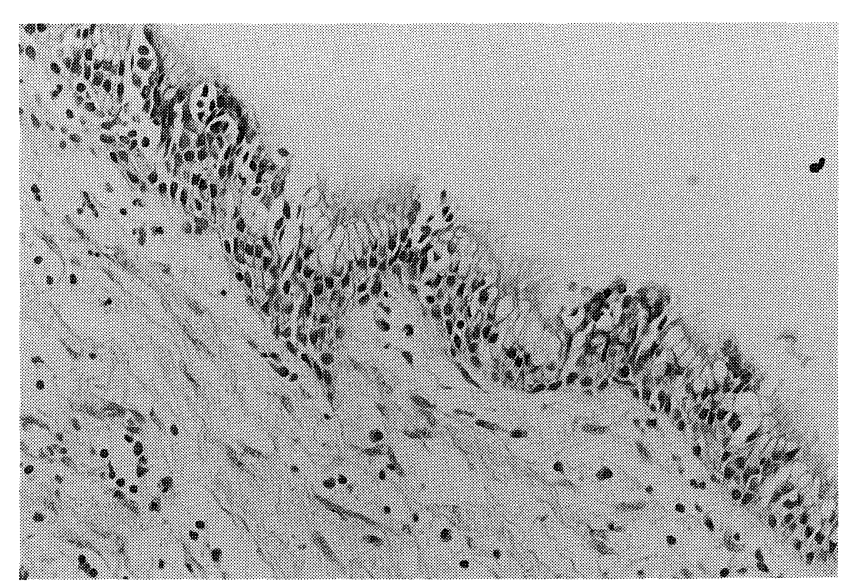

Figure 5. The cyst wall was lined with ciliated bronchial epithelium (HE stain, $\times 200)$.

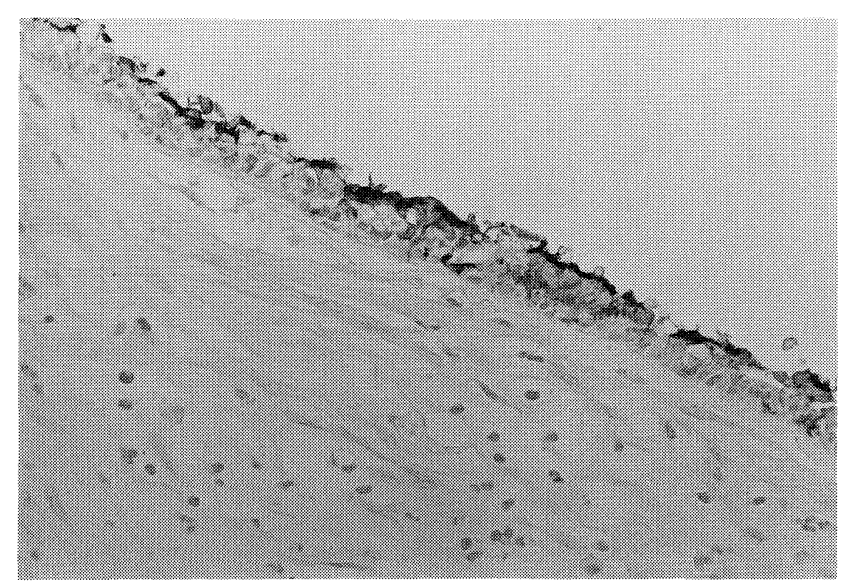

Figure 6. Immunohistochemical staining with anti CA19-9 monoclonal antibody. The ciliated bronchial epithelium was positive for CA19-9 $(\times 200)$.

fluids into the serum is responsible for increased levels in the serum. In this case, CA19-9 was demonstrated positive inside bronchial glands, epithelial cells of bronchial glands, and ciliated bronchial epithelial cells in the cyst. Therefore, we assume a common reason for the increase of CA19-9 between cyst fluid and serum. After resection, the serum level of CA199 returned to normal range, indicating that the bronchogenic cyst had caused the increased serum level of CA19-9 in this case.

Patients with bronchogenic cysts usually have no symptoms: these cysts are revealed during health examinations by chest X-ray films (2-4). To the best of our knowledge, only two previous cases have been followed up by chest X-ray films retrospectively $(12,19)$. In one case, Takagi et al were unable to find abnormalities in an earlier chest X-ray (19), because the bronchogenic cyst was located in the middle lobe and abnormalities behind the lower vessels and bronchus are not typically visible in standard chest X-ray film. However, in another case, there had been a vacant cyst before the mass shadow appeared in the chest X-ray film (12), and in the present case, we were able to identify a vacant cyst in the chest X-ray film taken one year previously, a cyst which increased in size to $8 \mathrm{~cm}$ within a year. These two cases suggest that the same bronchogenic cyst can demonstrate various abnormalities in chest X-ray films over a short period of time.

In the present case, it is important to discuss why the cyst became so large over a relatively short term. Though examinations for bacteria were negative, local infection might have played an important role in obstructing the formally patent bronchial communications because the fluid glucose was $0 \mathrm{mg}$ / $\mathrm{dl}$ and leukocyte count was $51,800 / \mathrm{mm}^{3}$. Furthermore, pathological findings revealed post inflammatory changes between the cyst wall and the lung. These findings could mean that the inflammatory changes blocked the communication between the cyst and airways, and that the cyst became enlarged due to accumulation of fluid inside the cyst.

Finally, it is important to emphasize two points in this unique bronchogenic cyst case: CA19-9 levels in both the serum and the cyst fluid were high; and a large mass shadow will be visible on chest X-ray film, when bronchogenic cysts have interrupted a patent bronchial communication, presumably because of accumulated fluid inside the cyst. Therefore, internists should bear in mind that, while bronchogenic cyst is a single-symptom condition, it can display a variety of $\mathrm{X}$-ray shadows in even one patient in a relatively short term. This case is important for consideration of the natural history of bronchogenic cysts.

Acknowledgements: The authors thank Dr. Yuichiro Fukasawa, Department of the Pathology, Sapporo City Hospital, for his excellent technical assistance.

\section{References}

1) Morrison IM. Tumours and cysts of the mediastinum. Thorax 13: 294, 1958.

2) Maier HC. Bronchogenic cysts of the mediastinum. Ann Surg 127: 476, 1948.

3) Eraklis AJ, Griscom NT, McGovern JB. Bronchogenic cysts of the mediastinum in infancy. N Engl J Med 281: 1150, 1969.

4) Coselli MP, de Ipolyi P, Bloss RS, Diaz RJ, Fitzgerald JB. Bronchogenic cysts above and below the diaphragm: report of eight cases. Ann Thorac Surg 44: 491, 1987.

5) Koprowski H, Steptewski Z, Mitchell K, Herlyn M, Herlyn D, Fuhrer P. Colorectal carcinoma antigens detected by hybridoma antibodies. Somatic Cell Genet 5: 957, 1979.

6) Gupta MK, Arciaga R, Bocci L, Tubbs R, Bukowski R, Deodhar SD. Measurement of a monoclonal-antibody-defined antigen (CA19-9) in the sera of patients with malignant and nonmalignant diseases. Cancer $\mathbf{5 6}$ : 277, 1985.

7) Buccheri GF, Ferrigno D, Sartoris AM, Violante B, Vola F, Curcio A. Tumor markers in bronchogenic carcinoma. Superiority of tissue polypeptide antigen to carcinoembryonic antigen and carbohydrate antigenic determinant 19-9. Cancer 60: 42, 1987.

8) Okubo A, Sone S, Ogushi F, et al. A case of bronchogenic cyst with high production of antigen CA19-9. Cancer 63: 1994, 1989.

9) Uyama T, Monden Y, Sumitomo M, et al. CEA and CA19-9 in benign pulmonary or mediastinal cystic lesions. J Surg Oncol 41: 103, 1989.

10) Sugano K, Ohkura $H$, Matsuda A, et al. Bronchogenic lung cyst with 


\section{ToKUCHI et al}

elevated serum type 1 chain related carbohydrate antigens CA19-9, CA50 and FH-7. Jpn J Clin Oncol 20: 182, 1990.

11) Ferrari E, Taillan B, Jourdan J, Isetta C, Dujardin P, Morand P. Intrapericardial bronchogenic cyst; an unusual cause of CA19-9 increase. Eur J Med 1: 122, 1992 (letter: see comments).

12) Ohkouchi M, Akizuki N, Jin Y, Ichioka M, Marumo F. Bronchial cyst in a patient with a high serum CA19-9 concentration that fluctuated with the cyst fluid volume. Nippon Kyobu Shikkan Gakkai Zazzhi 34: 482, 1996 (Abstract in English).

13) Nakamura A, Uchiyama Y, Yamaoka N, Ide S, Yamashita H. A resected case of bronchogenic cyst of the left hemidiaphragm with elevated serum CA19-9. Nippon Kyobu Geka Gakkai Zasshi 45: 79, 1997 (Abstract in English).

14) O'Rahilly R, Muller F. Chevalier Jackson lecture. Respiratory and alimentary relations in staged human embryos. New embryological data and congenital anomalies. Ann Otol Rhinol Laryngol 93: 421, 1984.

15) Luck SR, Reynolds M, Raffensperger JG. Congenital bronchopulmonary malformations. Curr Probl Surg 23: 245, 1986.

16) St-Georges R, Deslauriers J, Duranceau A, et al. Clinical spectrum of bronchogenic cysts of the mediastinum and lung in the adult. Ann Thorac Surg 52: 6, 1991.

17) Atkinson BF, Ernst CS, Herlyn M, Steplewski Z, Sears HF, Koprowski $\mathrm{H}$. Gastrointestinal cancer associated antigen immunoperoxidase assay. Cancer Res 42: 4820, 1982.

18) Arakawa $Y$, Ariga H, Kano M, Matsuo $Y$, Honda T, Morita K. Determination and significance of a new carbohydrate antigen CA19-9 in digestive system cancers. Jpn J Med 24: 121, 1985.

19) Takagi H, Kan N, Motoyama M, Hara M, et al. A case of bronchogenic cyst simulating rapidly growing pulmonary tumor. Nippon Kyoubu Rinsyou (Jpn J Chest Dis) 42: 958, 1983 (Abstract in English). 